\title{
LIBERDADES CIVIS OU SEGURANÇA: UM PARADOXO JURÍDICO-POLÍTICO MODERNO
}

\author{
CIVIL LIBERTIES OR SECURITY: \\ A MODERN LEGAL AND POLITICAL PARADOX
}

Guilherme Arruda ARANHA ${ }^{1}$

Artigo recebido em: 07/07/2016

Artigo aprovado em: 29/08/2016

RESUMO: O artigo aborda o paradoxo da modernidade que se instaura com a proteção jurídica das liberdades civis de um lado e as exigências de segurança e previsibilidade de outro. Aborda, ainda, a importância da literatura como forma não só de compreender a diversidade humana mas também de cultiva a empatia e a solidariedade em relação a essa diversidade. O artigo não se destina a oferecer uma equação capaz de superar o paradoxo mencionado, mas sim em reconhecer a sua existência como estratégia para não permitir que as liberdades civis sejam sufocadas pela exigência de previsibilidade e segurança.

PALAVRAS-CHAVE: Modernidade, liberdades civis, previsibilidade, segurança, literatura. 
ABSTRACT: The article discusses the modern paradox that is established with the legal protection of civil liberties on one side and the requirements of security and predictability on the other. It also addresses the importance of literature as a way to understand human diversity and a way of cultivating empathy for this diversity. The article does intends to provide an equation able to overcome the mentioned paradox, but to recognize its existence as a strategy not to let civil liberties being suppressed by the requirement of predictability and security.

KEY WORDS: Modernity, civil liberties, predictability, security, literature 


\section{Introdução}

O presente artigo possui dois objetivos que se articulam. O primeiro deles é demonstrar que a ciência moderna, constituída por uma metodologia que busca descrever as leis causais da natureza, e preocupada com a exploração técnica e matemática do mundo, resultou na pulverização do conhecimento em disciplinas especializadas e no vertiginoso desenvolvimento tecnológico do qual somos testemunhas. Mas a ciência moderna, diferentemente do que já se acreditou, não é valorativamente neutra. Um de seus valores de fundo é a previsibilidade. Seguindo essa lógica, até o ser humano é transformado em um objeto e reduzido a um corpo anatomicamente decomposto e analisável. Ao mesmo tempo, a lógica da previsibilidade científica se transforma rapidamente em um valor social e se exprime sobretudo pelo anseio de segurança nas relações interpessoais. O problema - e é isso o que o artigo pretende demonstrar - é que a insegurança é geralmente associada e atribuída ao "diferente", àquele que não se enquadra nos padrões da cultura dominante, o que tem resultado em uma política punitivista e de crescente encarceramento, sobretudo daquela parcela da população que não apresenta os traços da cultura dominante e que, portanto, é vista como ameaça. Assim, a proteção jurídica das liberdades civis, que marca o declínio das monarquias despóticas do século XVIII e o surgimento dos Estados liberais do século XIX, se vê em confronto, desde o início de sua positivação, com a exigência paradoxal de mais segurança e previsibilidade social.

O segundo objetivo do artigo é demonstrar, em contraposição, que a dimensão subjetiva do ser humano, pouco explorada pela ciência moderna, vem sendo investigada há quatro séculos pela arte do romance. O que se pode concluir com isso é, em primeiro lugar, que a educação formal de um ser humano - e penso no jurista em particular - não pode se reduzir à técnica, à dogmática e a algumas concepções teórico-filosóficas destinadas apenas a reforçar determinados conhecimentos restritos à sua área, mas deve ir além e contar também com um repertório narrativo e literário, apto a alargar o horizonte existencial do profissional. Embora a literatura não possa solucionar o paradoxo entre a proteção das liberdades individuais de um lado e o desejo de segurança e previsibilidade de outro, ela pode ajudar a despertar a sensibilidade e alertar para os perigos que rondam a tendência política de sufocar as liberdades civis em nome da segurança. 


\section{A modernidade literária de Miguel de Cervantes: para além da ciência e da filosofia}

Em um ensaio intitulado "A herança depreciada de Cervantes", o romancista e crítico literário Milan Kundera concorda com algo que já se disse inúmeras vezes acerca da modernidade, inaugurada par Galileu e Descartes. A saber, a ciência moderna desenvolveu-se ao longo dos últimos quatrocentos anos em disciplinas cada vez mais especializadas e reduziu o mundo a um objeto de exploração técnica e matemática, excluindo de seu horizonte o mundo concreto da vida. Um aspecto sombrio desse desenvolvimento científico foi aquilo que Husserl chamou de "o esquecimento do ser", isto é, a transformação do ser humano em uma simples coisa para as forças irresistíveis da técnica, da política e da história, que o ultrapassam e o possuem. Para essas forças, o ser concreto é eclipsado e esquecido, tornando-se descartável.

A originalidade de Kundera, porém, consiste em perceber que, além de Galileu e Descartes, Miguel de Cervantes também foi um dos fundadores dos tempos modernos. Segundo Kundera, todos os grandes temas existenciais analisados em Ser e tempo, e que Heidegger julgava abandonados pela filosofia europeia anterior, foram desvendados, mostrados e esclarecidos por quatro séculos de romance. A herança de Cervantes, acrescenta Kundera, é tão significativa quanto as demais. E se é mesmo correto afirmar que a ciência e a filosofia modernas se esqueceram do ser, talvez seja ainda mais relevante notar que, a partir de Cervantes, se formou uma grande arte literária cuja característica primordial é justamente a exploração desse ser esquecido. De acordo com Kundera:

\footnotetext{
(...) o romance descobriu, a sua própria maneira, por sua própria lógica, os diferentes aspectos da existência: com os contemporâneos de Cervantes, ele se pergunta o que é a aventura; com Samuel Richardson, começa a examinar 'o que se passa no interior', a desvendar a vida secreta dos sentimentos; com Balzac, descobre o enraizamento do homem na História; com Flaubert, explora a terra até então incógnita do cotidiano; com Tolstói, inclina-se sobre a intervenção do irracional nas decisões e no comportamento humanos. Ele sonda o tempo: o inapreensível momento passados com Marcel Proust; o inapreensível momento presente com James Joyce. Interroga, com Thomas Mann, o papel dos mitos que, vindos do começo dos tempos, teleguiam nossos passos etc. etc. (KUNDERA, 2009, p. 12-13).
}

A tese central de Kundera é que a modernidade, ao desligar-se do prin- 
cípio da autoridade divina, característica do período teocêntrico, fragmentou-se em uma miríade de verdades relativas e mergulhou em uma angustiante ambiguidade. A ciência e a filosofia logo tentaram substituir as antigas certezas divinas, agora naufragadas, por certezas fincadas no próprio ser humano e garantidas pela razão. A literatura moderna, porém, riu desde o início dessa tentativa filosófica e científica e garantiu, tanto nos momentos mais bem humorados quanto nos mais sombrios, quatro séculos de investigação do ser. Cito novamente Kundera pela beleza de suas palavras:

Quando Deus deixava lentamente o lugar de onde tinha dirigido o universo e sua ordem de valores, separara o bem do mal e dera um sentido a cada coisa, Dom Quixote saiu de sua casa e não teve mais condições de reconhecer o mundo. Este, na ausência do Juiz Supremo, surgiu subitamente numa temível ambiguidade; a única Verdade divina se decompôs em centenas de verdades relativas que os homens dividiram entre si. Assim, o mundo dos tempos modernos nasceu e, com ele, o romance, sua imagem e modelo (KUNDERA, 2009, p. 13-14).

\section{O início da modernidade no pensamento jurídico-político}

Também o universo jurídico possui as pedras angulares da sua modernidade: Hobbes primeiro, Locke e Rousseau na sequência. A despeito das marcantes diferenças entre eles, todos contribuem, cada um a seu modo, para repensar as questões da origem e dos limites do poder soberano, trazendo a esperança da autonomia do poder político e fornecendo material de reflexão para a ulterior construção do moderno constitucionalismo do final do século XVIII.

Tampouco o direito moderno escapa à ambivalência que o caracteriza. Uma das maiores criações do direito moderno é, sem dúvida, a limitação do exercício do poder político em função das liberdades civis, tornadas garantias fundamentais nas ordens jurídicas de inspiração burguesa e liberal, e que se espalharam pelos Estados democráticos, em diferentes matizes e intensidades, a partir da Independência dos Estados Unidos (1776) e da Revolução Francesa (1789). A moderna proteção das liberdades civis, contudo, vê-se frequentemente ameaçada pela exigência de previsibilidade e segurança. A supervalorização da previsibilidade, aliás, é uma consequência do desenvolvimento metodológico da ciência moderna e que passa a ser reivindicada também pelas teorias jurídicas nascentes. A segurança, por sua vez, é o correlato político e 
axiológico da supervalorização científica da previsibilidade: o que é previsível é seguro e onde há segurança, há ordem e paz. Previsibilidade e segurança tornam-se, assim, valores de fundo não apenas da ciência, mas também dos modernos ordenamentos jurídicos.

Se a prática jurídica na Europa do século XVIII, com múltiplas fontes do direito sem hierarquia entre elas, era vista como confusa, caótica, arbitrária e não-sistemática, o Código Civil francês de 1804 (Código de Napoleão) marca o início de uma nova era. De acordo com a nascente ciência dogmática do direito, o ordenamento jurídico codificado passou a ser visto como um sistema unitário, completo e coerente, capaz de garantir segurança e certeza jurídicas e, portanto, previsibilidade.

\section{A política da previsibilidade no mundo moderno}

Hannah Arendt soube identificar o compromisso com o previsível no pensamento político e filosófico modernos. Ela afirma, em A condição humana, que o mundo moderno transformou-se no mundo do homo faber, ou seja, um mundo dominado pelo trabalho, entendido como atividade marcada pela previsibilidade e pela relação meio/ fim. Enquanto o mundo dos antigos era o mundo da ação - definida por Arendt como atividade política, mediada pela palavra pública e pelo debate, caracterizado pelo agir conjunto e pela imprevisibilidade -, o mundo moderno do homo faber, ao contrário, é marcado pela instrumentalização da política, do direito, da ética e mesmo da natureza. Esta última, desvalorizada em si mesma e reduzida à condição de matéria prima, um bem "útil" para a produção de mercadorias, perde seu valor intrínseco ao ser brutalmente degradada.

Recorde-se de que Maquiavel avaliava o bom político pelo resultado de suas obras (o que é um tanto mais complexo do que afirmar que "os fins justificam os meios", conforme a famosa simplificação a ele atribuída). Para Hobbes, o direito seria uma criação racional capaz de proteger a vida contra a agressão dos outros e, por isso mesmo, o via como instrumento de atuação do homem sobre o homem. Aliás, desde Hobbes, a teoria jurídica moderna considera o direito o principal instrumento através do qual as forças políticas, que têm nas mãos o poder dominante em uma determinada sociedade, exercem o próprio poder. Nem mesmo Kant, no que diz respeito à ética, logrou superar a mentalidade do homo faber. A sua formulação, segundo a qual o ser humano é um fim em si mesmo, é também paradoxal, conforme argumenta Ferraz Junior: 
A ideia de um fim em si mesmo, ou seja, a ideia de um fim que não é mais meio para outro fim, é um paradoxo, porque todo fim nessa concepção deveria ser meio para um fim subsequente. A ideia de um fim em si mesmo foi formulada por Kant, que tentou resolver o dilema dessa tragédia. Kant colocou-nos diante da ideia de que o homem nessa concepção utilitária é afinal aquele que é um fim em si mesmo. Daí sua famosa concepção de que o homem nunca deve ser objeto para outro homem. A proposta de Kant, contudo, não resolve o problema, mesmo porque, no momento em que colocamos o homem como centro do mundo, como o único fim por si, portanto como a única coisa valiosa por si, todo o restante torna-se algo banal, não valioso, salvo quando tem um sentido para o homem, salvo quando é instrumento para o homem. Em outras palavras, alguma coisa só terá sentido se contiver trabalho humano, pois se instrumentaliza. No mundo do homo faber, a esfera pública, que na Antiguidade era a esfera do homem político, passa a ser a esfera do mercador. A concepção de que o homem é um construtor, um fabricante de coisas, conduz à conclusão de que o homem só consegue relacionar-se devidamente com outras pessoas, trocando produtos com elas (FERRAZ JUNIOR, 2001, p. 25).

A previsibilidade é, portanto, um dos valores cardeais do mundo burguês do homo faber. E mesmo levando em consideração as intensas mudanças propiciadas pelas revoluções industriais do século XIX, bem como pela revolução informática que se observa desde o fim do século XX, continuamos herdeiros diretos da supervalorização da previsibilidade. O discurso da previsibilidade, por sua vez, se revela onipresente na indústria da segurança, nos mecanismos tecnológicos de vigilância e nos discursos políticos. A previsibilidade permeia, inclusive, as relações interpessoais.

Note-se, porém, que segurança e liberdade são valores incompatíveis: quanto maior a segurança de um povo, menor será a sua liberdade. Não se trata, contudo, de escolher explicitamente e conscientemente entre uma ou outra. $\mathrm{O}$ que se instaura na modernidade, a partir da dicotomia segurança versus liberdades civis, é um paradoxo que se manifesta, ainda hoje, com grande intensidade.

\section{$5 \mathrm{O}$ embate entre liberdades civis e segurança}

A fim de melhor ilustrar o paradoxo que se instaura entre segurança e liberdades civis, convém lembrar que estas últimas têm diversos nomes. Elas 
constituem a liberdade dos modernos (em oposição à liberdade dos antigos), ou, ainda, nos dizeres de Isaiah Berlin, a liberdade negativa, porque exercida em relação aos outros e, sobretudo, em relação ao Estado (Cf. Berlim, 2002, p. 228-272). A liberdade, como alerta o próprio Berlin, é termo poroso, com mais de duzentos sentidos registrados pelos historiadores das ideias. Neste artigo, o termo se reduz a apenas uma de suas acepções: trata-se, aqui, da liberdade como uma meta "negativa" de evitar a interferência do Estado nas crenças, nos valores e sobretudo na ação dos indivíduos. A formulação filosófica de seu conteúdo esteve a cargo dos jusnaturalistas modernos, sobretudo John Locke, para quem essa liberdade era considerada um direito inato e inalienável e deveria, portanto, constituir um limite natural ao exercício político da autoridade soberana. $\mathrm{O}$ impacto desse ideal jusnaturalista se fez presente na Declaração de Independência dos Estados Unidos (1776) e na francesa Declaração dos Direitos do Homem e do Cidadão (1789) - sem menosprezar, evidentemente, a influência histórica da Revolução Gloriosa, que resultou na elaboração do Bill of Rights já no século XVII -, e que influenciam até hoje as Constituições das modernas democracias liberais. Finalmente, aqueles que eram denominados direitos inatos no século XVIII, passam a ser renomeados como liberdades civis ou, ainda, mais recentemente, como direitos humanos de primeira geração (para usar a controversa denominação proposta por Karel Vasak).

Em suma, as liberdades civis representam a ênfase no indivíduo, no direito à vida, à liberdade religiosa, de auto-realização, de opinião e no direito de buscar a própria felicidade, mesmo que seja em oposição aos valores da tradição. Ao Estado compete não se intrometer nessas questões de ordem individual. Não obstante, compete ao mesmo Estado garantir segurança. E garantir segurança é garantir também previsibilidade. E, por fim, garantir segurança e previsibilidade (ou pelo menos vender a ilusão de que as garante) é mais fácil à medida em que o Estado limita (e às vezes suspende) as liberdades individuais. O Estado liberal transforma-se assim em um prestidigitador, mostrando em uma das mãos as garantias jurídicas dos direitos individuais e fazendo-as sumir com a outra. E toda tentativa de reformar esse Estado para que ele, enfim, garanta as liberdades civis, está fadada a redundar novamente na limitação dessas mesmas liberdades, como um cão que persegue o próprio rabo. Esse mecanismo ficou ainda mais evidente quando, em 2013, Edward Snowden revelou que o programa de vigilância global da Agência de Segurança Nacional dos Estados Unidos vasculha intensivamente não apenas suspeitos de terrorismo mas também a vida de 
cidadãos comuns de todo o mundo. Por meio de um imenso banco de dados, é notório que o governo estadunidense possui, hoje, mais informações acerca da vida pessoal dos cidadãos (e não apenas de seus próprios cidadãos), do que jamais havia sonhado qualquer regime autoritário que tenha existindo antes da era da informática.

Outro aspecto do paradoxo aqui examinado é que, curiosamente, vivemos em um mundo pacificado, como jamais havia acontecido na história da humanidade, mas que se faz acompanhar do aumento da sensação de insegurança. De acordo com o filósofo francês Gilles Lipovetsky (que toma como ponto de partida O processo civilizador, de Norbert Elias), sociedades que eram antes reguladas pela honra, pela vingança, pela violência e pela crueldade, com o advento do Estado moderno, aos poucos se transformaram em sociedades policiadas e pacificadas. A monopolização do uso da força, somada ao processo de abrandamento dos costumes, resultou no desaparecimento oficial de duelos e suplícios, na extinção da pena de morte (ou na diminuição dos condenados à pena capital onde ela não chegou ainda a ser extinta), na queda do infanticídio e na drástica diminuição de homicídios e crimes de sangue. Argumenta Lipovetsky:

Hoje em dia é celebre a tese de N. Elias a respeito da humanização do comportamento: sociedades nas quais a belicosidade e a violência em relação ao outro se desenvolviam livremente passaram a ser sociedades em que os impulsos agressivos se encontram reprimidos, refreados porque incompatíveis com a 'diferenciação', cada vez mais encorajada pelas funções sociais de um lado e, de outro, pelo monopólio do constrangimento físico do Estado moderno. Quando não existe nenhum monopólio militar e policial e, portanto, a insegurança é constante, a violência individual e a agressividade são necessidades vitais (LIPOVETSKY, 2005, p. 160-161).

Não obstante, Lipovetsky vai além da tese de Norbert Elias para afirmar que a sensação de insegurança é, hoje, maior do que nunca. Em outras palavras, quanto mais pacificada é uma sociedade, maior a sensação de insegurança que os indivíduos sentem. Tal fenômeno, contudo, não é apenas mera consequência do monopólio do uso da força pelo Estado moderno, mas resulta, também, do crescimento do mercado, que é o complemento necessário desse Estado. Assim, tão importante quanto o fenômeno da monopolização do uso da força é o crescimento da esfera do mercador, isto é, da esfera de ação do homo faber, que, 
como vimos, enaltece a previsibilidade. Ainda segundo Lipovetsky:

(...) é o Estado moderno e seu complemento, o mercado, que de maneira convergente e indissociável, contribuíram para a emergência de uma nova lógica social, de um novo significado do relacionamento humano, tornando inelutável a longo prazo o declínio da violência privada. De fato, foi a ação conjugada do Estado moderno e do mercado que permitiu a grande fratura, que hoje nos separa para sempre das sociedades tradicionais, e o aparecimento de um tipo de sociedade na qual o indivíduo se considera a finalidade última e não existe a não ser para si mesmo (LIPOVETSKY, 2005, p. 162).

Note-se que a noção kantiana segundo a qual o ser humano é um fim em si mesmo encontra aí sua mais hedonista realização. Mas note-se, também, que a assimilação do ideal kantiano é feito por vias transversas e muito aquém das pretensões filosóficas de Kant: não se trata mais do imperativo categórico que exige tratarmos o outro como um fim em si mesmo; não se trata mais da norma moral que devemos nos impor autonomamente em função do respeito ao outro. Trata-se, antes disso, de algo muito menos nobre e muito mais prosaico: o ser humano é um fim em si mesmo porque o ego se vê no centro do mundo. O ideal kantiano descambou em uma reivindicação individualista e narcísica que se manifesta no consumismo e na aspiração contemporânea, sem precedentes históricos, pelo dinheiro, pela fama, pelo bem-estar, pela saúde, pela propriedade e pela ostentação de tudo isso (mesmo quando a ostentação não passa de mero simulacro, como acontece nos reality-shows, no funk ostentação, nas redes sociais e na disseminação mundial da cultura dos retratos selfies). Ainda segundo Lipovetsky:

Cada vez mais voltados para as preocupações particulares, os indivíduos se pacificam não por ética, mas, sim, por hiperabsorção individualista: nas sociedades que impulsionam o bem-estar e a realização de si mesmo, os indivíduos, é claro, têm mais desejo de encontrar a si mesmos, de se auscultarem, de se 'drogar' com viagens, música, esportes, espetáculos em vez de se defrontar fisicamente. A repulsão profunda e geral dos nossos contemporâneos pelas condutas violentas é função dessa disseminação hedonista e informal do todo social realizada pelo reinado do automóvel, da mídia, do lazer (LIPOVETSKY, 2005, p. 169). 
O reverso das aspirações individualizadas, narcísicas e pacificadas é o desejo pela segurança, que anda de mãos dadas com o desinteresse pela coisa pública e pela política, resultando no menosprezo pela busca de soluções coletivas para problemas vivenciados como se fossem individuais, como é o caso da própria violência. As pseudo-soluções individuais tornam-se objeto de consumo e passam a ser vendidas pela indústria do medo: um carro blindado com vidros escuros, uma casa em um condomínio fechado e murado e um sistema de câmeras de vigilância, de preferência bem caros, parecem apaziguar os espíritos amedrontados e individualistas, quando na verdade apenas afastam (ou fingem afastar) o problema da violência residual para longe dos olhos, para a rua de baixo, para o outro bairro, para a distante periferia. Quanto à política, o que se exige dela não é a discussão das causas da violência residual e a implementação de mecanismos capazes de superar o problema de modo coletivo, inclusive nos bairros periféricos. Tudo se passa como se bastassem mais leis penais, penas mais rígidas e mais polícia na rua.

Desse modo, agora distanciados de interesses e causas coletivas, e pacificados pelo Estado e pelo mercado, os indivíduos passam a desejar o Estado policial, mesmo que seja para depois denunciar a sua natureza repressiva e seus excessos. Comprovam-no o inflacionamento da legislação penal, que vem ampliando os tipos penais de condutas não-violentas e que resulta no crescente encarceramento da população.

Nesse sentido, o Brasil acompanha a tendência dos Estados Unidos: já temos a quarta maior população carcerária do mundo, o que não se deve somente ao crescimento populacional. Segundo o Levantamento Nacional de Informações Penitenciárias (INFOPEN), de dezembro de 2014, elaborado pelo Departamento Penitenciário Nacional (DEPEN), nos primeiros 14 anos do século XXI a população carcerária aumentou $267,32 \%$, muito acima da média do crescimento populacional. Enquanto a população carcerária cresce, em média, 7\% ao ano, o crescimento populacional é de apenas $1,1 \%$ ao ano (infopen.gov.br).

Por outro lado, ao mesmo tempo em que se expande a legislação penal sobre condutas não violentas, menos de $8 \%$ dos homicídios ocorridos no Brasil, segundo dados da Anistia Internacional, chegam a virar processo criminal ${ }^{2}$. Em suma, prende-se muito e prende-se mal.

Lipovetsky reforça os argumentos ora apresentados:

2 Disponível em: https://anistia.org.br/imprensa/na-midia/violencia-brasil-mata-82-jovens-por-dia/ 
Multiplicação das leis penais, crescimento dos efetivos e dos poderes da polícia, vigilância sistemática das populações são os efeitos fatais de uma sociedades em que a violência é desvalorizada e em que simultaneamente aumenta a necessidade de segurança pública. O Estado moderno criou o indivíduo socialmente desligado dos seus semelhantes, mas este, em troca, cria por seu isolamento, sua ausência de belicosidade, seu medo da violência, as condições constantes do crescimento da força pública. Quanto mais os indivíduos se sentem livres por si mesmos, mais exigem proteção regular, sem falha, por parte dos órgãos estatais; quanto mais eles exercem a brutalidade, mais requisitam o aumento das forças de segurança: a partir daí a humanização dos costumes pode ser interpretada como um processo que visa destituir os indivíduos dos princípios refratários à hegemonia do poder total, que tem o projeto de colocar a sociedade sob a tutela completa do Estado (LIPOVETSKY, 2005, p. 162).

O aumento da sensação de medo em nossas sociedades contemporâneas e ocidentais, ao contrário do que pode parecer, não significa que vivemos no mais inseguro dos mundos. Como já foi dito, várias práticas violentas foram extintas ou, ao menos, são duramente reprimidas pelo direito estatal. Por outro lado, e isso parece desestabilizar o indivíduo contemporâneo, não só não existe mundo totalmente seguro como, se existisse, seria indesejável, pois nele não haveria espaço para o exercício da liberdade, da criação artística, filosófica e científica e da transformação e renovação.

Em outras palavras, à medida em que as condutas se pacificam e os crimes violentos tornam-se mais escassos, paradoxalmente e legislação penal se intensifica e os encarceramentos tornam-se mais frequentes para fazer frente a constantes apelos por mais segurança. Além disso, o maior alvo desses encarceramentos, no Brasil, é a população pobre e negra, justamente aquela que não apresenta os estereótipos tranquilizadores da cultura dominante (homem, adulto, branco, que se situa da classe média para cima e ocupa os principais cargos das empresas, da política, das universidades, do jornalismo e, é claro, do poder judiciário) e que, portanto, aparece a seus olhos como ameaça de violência pela fissura de previsibilidade.

Enquanto o racismo inconsciente e "naturalizado" de parte da população acredita que negros e pobres são mais propensos a práticas criminosas, a realidade é bem diversa. Uma pesquisa realizada pelo Núcleo de Estudos da 
Violência (NEV), da Universidade de São Paulo (USP), em 1992-1993, já revelava que réus brancos que agridem vítimas da mesma etnia têm maior probabilidade de absolvição (54,8\%) do que de condenação (42,2\%). Quando, porém, o agressor é negro e a vítima, branca, o quadro se inverte e a proporção de condenados $(57,8 \%)$ passa a ser superior a de absolvidos (45,2\%). A mesma pesquisa indica, ainda, maior incidência de prisões em flagrante para réus negros $(58,1 \%)$ em comparação aos réus brancos $(46,0 \%)^{3}$. São ainda piores as estatísticas apresentadas no $3^{\circ}$ Relatório Sobre o Perfil dos Réus Atendidos nas Audiências de Custódia, produzido pela Defensoria Pública do Rio de Janeiro em 2016: as chances de uma pessoa branca presa em flagrante ser solta após a audiência de custódia são $32 \%$ maiores que as de pessoas negras ou pardas ${ }^{4}$. Finalmente, segundo dados do IBGE de 2010, 75\% da população carcerária brasileira não havia chegado sequer ao ensino médio, o que é uma característica da população pobre. Não bastasse isso, negros e pobres são também as maiores vítimas da violência. De acordo com a Anistia Internacional ${ }^{5}, 56$ mil pessoas foram assassinadas no Brasil em 2012, sendo 30 mil jovens. Destes 30 mil, 77\% eram homens negros e pobres, entre 15 e 29 anos de idade. Nenhuma dessas mortes, contudo, é noticiada pela imprensa, relegando à invisibilidade uma parcela expressiva da população.

Em suma, o incremento da política punitivista e de crescente encarceramento, sobretudo daquela parcela da população que não apresenta os traços da cultura dominante, é resultado do desejo de segurança e previsibilidade nas relações interpessoais e redunda na redução, quando não na privação, das liberdades civis. Redunda, também, em exclusão social, encarceramento e execução dos mais pobres, sobretudo se forem negros.

\section{Direitos humanos em um mundo intolerante}

Outro paradoxo das democracias modernas e liberais opõe o discurso da intolerância ao discurso do respeito aos direitos humanos. No Brasil, uma ampla parcela da população, disseminada em todas as classes sociais, define-se explicitamente contrária à proteção dos direitos humanos. Não é preciso consul-

${ }^{3}$ Disponível em: http://www.nevusp.org/portugues/index.php?option=com_content\&task=view\&id=1413\&ltemid=55

${ }^{4}$ Disponível em: http://jota.uol.com.br/audiencias-de-custodia-liberam-32-mais-brancos-que-negros-e-pardos

${ }^{5}$ Disponível em: https://anistia.org.br/imprensa/na-midia/violencia-brasil-mata-82-jovens-por-dia/ 
tar estatísticas: essa postura refratária aos direitos humanos revela-se cotidiana e incansavelmente nas conversas familiares e do comércio, em redes sociais, jornais, rádio, televisão, salas de aula e de professores etc. Na imensa maiorias desses discursos anti-direitos humanos o que se nota é o medo da insegurança e o desejo de se viver em uma sociedade cada vez mais segura. Contudo, o desejo de se viver em uma sociedade cada vez mais segura se expressa, paradoxalmente, em um discurso de recrudescimento da violência a ser exercida livre e arbitrariamente pelo braço armado do Estado. Não raro, o discurso pela reivindicação de mais segurança é acompanhado pela defesa de práticas de tortura e de pena de morte. É famoso o corolário desse pensamento: “bandido bom é bandido morto". Nesses casos, porém, é sempre o diferente, ou seja, o "desconhecido ameaçador" quem não precisaria ter seus direitos humanos respeitados. $\mathrm{O}$ mesmo raciocínio, porém, não vale para quem pertence à cultura dominante $\mathrm{e}$ comete um ilícito penal. O conto "O tradutor cleptomaníaco", do escritor húngaro Dezsö Kosztolányi (1885-1936), sintetiza essa lógica com humor e ironia ao defender um amigo habituado a furtar e que, sendo húngaro, havia sido preso em flagrante em Viena (onde era, portanto, um estranho):

Tentamos provar que ele era um cleptomaníaco e não um ladrão. Aquele que conhecemos geralmente é cleptomaníaco. Aquele que não conhecemos geralmente é ladrão. O tribunal não o conhecia; assim foi qualificado - ladrão, e condenado a dois anos de prisão (KOSZTOLÁNYI, 2016, p. 8).

Em suma, as democracias modernas são indissociáveis da proteção dos direitos humanos e, portanto, não se resumem apenas a um conjunto de gregas de procedimento ${ }^{6}$, mas também se assentam sobre valores, entre eles, o valor moral da tolerância e da solidariedade.

Para evitar mal entendidos, é preciso dizer que não penso na tolerância como uma pseudo-virtude arrogante em que aquilo que é tolerado "permanece", não obstante, "em posição de inferioridade em relação ao que é tido como norma" (Cf. Lins, 2005, p. 19-33). A tolerância consiste antes em um processo de pacificação das relações humanas e de aceitação do diferente, do outro, das

\footnotetext{
${ }^{6}$ Norberto Bobbio, por exemplo, em O futuro da democracia, menciona as regras abstratas que atribuem a um elevado número de cidadãos o direito de participar direta ou indiretamente das decisões coletivas, da regra da maioria (limitada, todavia, pelo respeito aos direitos humanos), e da existência de alternativas de escolher entre projetos distintos (Cf. BOBBIO, 2000, p. 30-32).
} 
minorias. E mesmo que não haja empatia nesse processo, ele é marcado pela não violência. A tolerância não se resume à aceitação de uma crença qualquer ou de um conteúdo específico, mas, sim, à possibilidade formal da diversidade de crenças. A tolerância não se confunde com a renúncia à própria opinião nem é sinônimo de neutralidade ou de aprovação de crenças contrárias às suas. Tampouco se deve tolerar o intolerável, porque seria contraditório abrir espaço para aqueles que não respeitam e até agridem os que não pensam como eles. O limite da tolerância é uma questão que exige discussão permanente, sempre dentro dos limites do Estado de Direito e do respeito aos direitos humanos.

Que a tolerância não seja praticada em regimes autocráticos e teocráticos é bastante evidente. Mas ela também não é uma virtude tão praticada quanto deveria ser nas modernas democracias. Norberto Bobbio reflete de modo conciso acerca da precariedade do exercício tolerante:

Se hoje existe uma ameaça à paz mundial, esta vem ainda uma vez do fanatismo, ou seja, da crença cega na própria verdade e na força capaz de impô-la. Inútil dar exemplos: podemos encontrá -la a cada dia diante dos olhos (BOBBIO, 2000, p. 51).

Desnecessário dizer que a frase escrita por Bobbio na década de 1980, continua hoje mais atual do que nunca. Novamente o que se nota é o paradoxo decorrente do exercício narcísico das liberdades civis: o indivíduo ensimesmado, que se considera um fim em si mesmo, vê no outro, no diferente, uma ameaça à sua individualidade e à previsibilidade de suas relações interpessoais, repetitivas e seguras. Assim, o diferente, o que está fora da medida do "normal", antes de ser tolerado passa a ser temido por sua pura existência.

\section{Conclusão: a força da literatura para uma educação solidária e democrática}

Como superar o medo pelo outro, pelo diferente? Como conciliar democracia e tolerância? Ou, de modo ainda mais ousado, como converter a desconfiança em solidariedade e empatia? O filósofo estadunidense Richard Rorty (1931-2007) aposta no poder emancipador da literatura e propõe uma utopia em que a narrativa ocupe um lugar de destaque em relação à teoria e ao sermão. Em seu livro Contingência, ironia e solidariedade, Rorty argumenta que a solidariedade não é o resultado nem da indagação filosófica nem da eliminação do preconceito 
em relação ao diferente, mas sim um objetivo a ser alcançado por meio da imaginação, mais precisamente pela capacidade imaginativa da narrativa ficcional e artística, a saber, o cinema, a história em quadrinhos, a novela de televisão, o jornalismo literário, o documentário dramatizado e, sobretudo, a literatura e, em especial, o romance. Estas artes narrativas, argumenta Rorty, nos fazem enxergar pessoas estranhas como semelhantes sofredores. Em outras palavras, a solidariedade não é "descoberta" pela razão teórica mas criada pelo poder narrativo, capaz de despertar a sensibilidade em relação à dor, ao sofrimento e à humilhação dos tipos que não nos são familiares. A arte narrativa é vista, então, como um processo de descrição detalhada, e de redescrição de quem somos nós mesmos, o que nos permite reconhecer aquele que é diferente como "mais um de nós" e não como simplesmente "eles". Ou seja, a narrativa faz com que o ser humano diferente de nós não seja mais visto como ameaça e sim como um semelhante sofredor. É por isso, conclui Rorty, que ao longo das últimas décadas as artes narrativas vêm substituindo, de modo sistemático e paulatino, a teoria, o tratado e o sermão como principais veículos de mudança e progresso moral (Cf. Rorty, 2007, p. 20-21). Um exemplo apontado por Rorty é redução do preconceito contra os homossexuais entre os mais jovens, nem tanto em função de um discurso teórico da aceitação quanto da empatia proporcionada pelas artes narrativas mais recentes. Importante frisar, ainda, que a guinada a favor das artes narrativas em relação ao tratado e à teoria significa a desistência da tentativa de abarcar todas as facetas da vida numa única visão e de descrevê-la com um único vocabulário.

Iniciamos esse artigo citando Kundera e, agora, voltamos a ele. Kundera - ele mesmo um tcheco e, como tal, vítima da ocupação russa em seu país - avança em sentido semelhante ao de Rorty ao lembrar que a arte do romance é incompatível com o mundo totalitário, e que ela só pode se desenvolver onde as ambivalências, e portanto a interrogação, a dúvida e a liberdade, são admitidas e não perseguidas. A arte literária é, assim, uma espécie de sabedoria da incerteza, capaz de lidar com a complexidade do mundo e com a diversidade dos indivíduos singular e concretamente considerados (Cf. Kundera, 2009, p. 14-15).

Não se trata, para Rorty e Kundera, de negar que a ciência moderna tenha se tornado demasiadamente especializada e que a filosofia moderna tenha se enveredado pela busca das condições do conhecimento confiável. As duas afirmações, que aparecem com frequência nas obras de tantos filósofos desde Husserl e Heidegger, estão corretas. A novidade, porém, é que Rorty e Kundera 
reconhecem um papel muito próprio da literatura. Para eles é também imprescindível a formação por meio da literatura e da narrativa, sob pena de o conhecimento técnico e teórico degradarem-se na prática sistemática da violência contra o diferente, resultando na banalização do mal.

O que se percebe, enfim, é que estudar o direito, a democracia e os direitos humanos, exige mais do que técnicas dogmáticas e conceitos jusfilosóficos: exige também o conhecimento da diversidade humana e o cultivo da empatia por essa diversidade. Para tanto, nada melhor do que a literatura. É ela, afinal, que nos faz perceber que a insegurança e a incerteza são inevitáveis e fazem parte da vida bem vivida. Como nos lembra João Guimarães Rosa, viver é muito perigoso. Ou ainda, o que a vida quer da gente é coragem.

A proposta final, portanto, não é oferecer uma equação capaz de superar o paradoxo entre as liberdades civis de um lado e a exigência de segurança e de previsibilidade de outro. Trata-se, antes, de reconhecer a existência do paradoxo e, com a ajuda da literatura, não deixar que as liberdades civis sejam sufocadas pela exigência totalitária de uma previsibilidade e segurança absolutas. O dia em que isso acontecer, a modernidade terá sucumbido e, de progresso tecnológico em progresso tecnológico, se degradado.

\section{Referências}

ARENDT, Hannah. A condição humana. 9. ed. Rio de Janeiro: Forense Universitária,1999.

BERLIN, Isaiah. Estudos sobre a humanidade: uma antologia de ensaios. São Paulo: Companhia das Letras, 2002.

BOBBIO, Norberto. O futuro da democracia. São Paulo: Paz e Terra, 2000.

FERRAZ JUNIOR, Tercio Sampaio. Introdução ao estudo do direito: técnica, decisão, dominação. São Paulo: Atlas, 2001.

KOSZTOLÁNYI, Dezsö. O tradutor cleptomaníaco e outras histórias de Kornél Esti. Tradução de Ladislao Szabo. São Paulo, Editora 34, 2016. 
KUNDERA, Milan. A arte do romance. São Paulo: Companhia das Letras, 2009.

LINS, Daniel. Tolerância ou imagem do pensamento? In: A tolerância e o intempestivo. PASSETI, Edson e OLIVEIRA, Salete (orgs.). Cotia, SP: Ateliê Editorial, 2005.

LIPOVETSKY, Gilles. A era do vazio. Barueri, SP: Manole, 2005.

RORTY, Richard. Contingência, ironia e solidariedade. São Paulo: Martins Martins Fontes, 2007. 